\title{
The PAD Class: a new paradigm for university classroom teaching
}

\section{Xuexin Zhang}

Xuexin Zhang, "The PAD Class: a new paradigm for university classroom teaching," Proc. SPIE 10452, 14th Conference on Education and Training in Optics and Photonics: ETOP 2017, 104521X (16 August 2017); doi: 10.1117/12.2270967

SDIE Event: 14th Conference on Education and Training in Optics and Photonics, ETOP 2017, 2017, Hangzhou, China 


\title{
The PAD Class, a new paradigm for university classroom teaching
}

\author{
Xuexin Zhang
}

Professor, Fudan University, Shanghai, Email: xuexinzhang@fudan.edu.cn

\begin{abstract}
The PAD Class (Presentation-Assimilation-Discussion) is a new paradigm for classroom teaching combining strengths of lecture and discussion. With half class time allocated for teacher's presentation and the other half for students' discussion, an assimilation stage was inserted between presentation and discussion for independent and individualized learning. Since its first success in 2014, the PAD method has gained national popularity in China and been successfully put into practice by thousands of college teachers in nearly all subjects, e.g., science, engineering, medical sciences, social sciences, humanities and arts. This paper analyzed the psychological and pedagogical rationales underlying the PAD Class to explicate its effectiveness in enhancing active learning.

Keyword: College Teaching; Assimilation; Lecture; Discussion; Active Learning; cooperative learning
\end{abstract}

\section{Introduction}

School education is the major sector of education. Core to school education is classroom teaching and central to classroom teaching is the teaching paradigm ${ }^{1}$. Across the whole world, classroom teaching in schools has been dominated by the lecturing paradigm for several centuries. It is well-recognized that lecturing is mainly a one-way communication that does not involve adequate student participation. In this

\footnotetext{
14th Conference on Education and Training in Optics and Photonics: ETOP 2017, edited by Xu Liu,

Xi-Cheng Zhang, Proc. of SPIE Vol. 10452, 104521X - (c) 2017 ICO, IEEE, OSA, SPIE

CCC code: $0277-786$ X/17/\$18 - doi: $10.1117 / 12.2270967$
} 
paradigm, the teachers' class presentation and the students' after-school learning are two separate processes. There is little interaction between teachers and students, the students accept passively, so it is hard for them to train out the thinking ability and the spirit of exploration.

Lecturing is a teaching paradigm that suits the industrial era where knowledge needs to be conveyed very efficiently. However, under the lecturing paradigm, students are not self-motivated and learning is not active. In the post-industrial era, education needs to foster key competence such as critical, creative thinking, collaboration and communication. Clearly, the lecturing paradigm is not capable for achieving such goals.

There is a major alternative teaching paradigm, referred to as collaborative learning, which is to introduce discussion in class and increase interactivity and student participation in learning. However, in actuality, discussion in collaborative learning is quite often hard to implement. Many students find it difficult to raise questions. Discussion often takes long time and students do not feel they learn enough content.

Compare and contrast the two major teaching paradigms, one can see that lecturing achieves systematic knowledge coverage and is very efficient in knowledge transmission. But the problem with it is that students has little control over the learning process and are mainly following the teacher to do imitative learning. In the collaborative learning paradigm, students are given the control to learn and the opportunity to learn from each other, learning in principle can be active but learning outcome often cannot be assured. Like two poles, the pros of one paradigm are exactly the cons of the other and vice versa.

That neither of the two major teaching paradigms is satisfactory is a universal problem that baffles teachers and students in all levels of classroom teaching. Classroom teaching in school is the most important form of learning in the society. 
For millions of teachers and students, their everyday behaviors in the classroom, the efficiency and outcomes of their teaching and learning processes, the quality of school education, are prescribed by and contingent on the teaching paradigm.

\section{The PAD Class teaching model}

When discussion is used in the classroom, it is typically implemented in the form of "Instant Discussion". That is, students are asked to discuss on the teaching content immediately after teacher's lecture. This way of operation violates the basic psychological principles of learning: students have not understood the content that they just heard, there is no time for thinking and assimilating the knowledge and less significant questions to raise, it is hard for the students to form specific viewpoints and opinions, the discussion is lack of depth and significance and difficult to obtain favorable results.

The "PAD class" is a new teaching model proposed by the author ${ }^{2}$. The point of departure of this paradigm is to modify "Instant Discussion" to "Delayed Discussion". The new paradigm consists of three major stages, Presentation, Assimilation, and Discussion. The teacher would present materials concisely. Students then have time for individual and independent study, to reflect upon what has been taught, to read the textbook and to write out what they learned. Finally, they form small groups of 4-6 students each, and discuss what they have learned. In the discussion, they help each other and leave difficult problems to the teacher.

Key to the procedure of "Delayed Discussion" is to let the students assimilate the taught content to a certain degree with independent study and thinking, before their carrying out group discussion so as to effectively improve the discussion quality. The PAD Class ensures that the students get adequate guidance. And the teacher presents only the framework, the key principles and basic concepts, leaving space for the students to explore. After their independent study, students test, clarify and revise 
their individual learning outcomes with peers in the group discussion, through collaborative learning.

\section{Operation of the PAD Class model}

Presentation: In traditional class, the teachers' presentation is exhaustive and covers all matters. It is generally considered that the more systematical, the more complete, the more profound, the more thorough, the more clear, the more specific, the more vivid, the more interesting and the more splendid the teachers teach, the better. In PAD Class, all of these concepts are reverted. The teacher should not teach too systematical, too complete, to exhaustive, too profound, too thorough, too clear, too specific, too vivid, to interesting and too splendid.

The principle of presentation in PAD is concise teaching and leaving blank which is shorted as CTLB. In PAD Class, the teachers have only half of the original time to teach the same content, so it can neither be detailed, nor have time to teach lively and interestingly, but should give concise, guiding and frame presentation, instruct the study objectives as well as the logic structure of chapters and their the relevance and the relationship with other content and the positions in the whole course. Guiding must be macroscopic.

The concise teaching of PAD is telling the students what to learn, why to learn and how to learn on the macroscopic level.

Assimilation: The main content of after-class study is reading, review, independent thinking and finishing homework, of which homework is a core step between presentation and discussion as well as the key for success of PAD. Homework is the most important tongs for implementing PAD in the early stage, so assignment of homework is very crucial. In-class PAD is more special, all steps are finished in class, so under the condition of limited time, the simple homework that is called "micro-homework" can be assigned. For example, raise a question for the 
students to write a simple comment, write a sentence for the students to translate, give a work for the students to find antonym or give an event for the students to think deeply and raise a view.

If the time is longer, it can ask the students to translate a paragraph, finish several exercises and write a short composition, etc. In cross-class PAD, the students have more time for study after class, so the in-depth homework can be assigned. The purpose of homework is guiding and urging after class review, ensuring understanding of basic content and making preparation for in depth and meaningful group discussion.

Discussion: At the beginning of the discussion stage, the teachers can briefly review the content of the previous class and requirements to the homework in 1-2 min before starting the discussion. The discussion is divided into 4 steps that are group discussion, selective examination by teacher, free question and summary of teacher, the sequence of which is important and shall not be changed.

The group discussion is normally carried out with 4 students as a group and lasts for 5-20 minutes. According to the homework, the students are required to learn from each other and solve problems together with regard to respective gains, puzzles and problems.

It subsequently enters whole class communication. The first step is selective examination by the teachers. The teachers randomly select 3 to 4 groups, and each group randomly select one student to stand up and share the essence of the discussion just now or raise the problems that haven't been solved, in the form of peer instruction ${ }^{3}$. The students shall face to the whole class and start with "our group" to express the viewpoints or problems of their group instead of themselves.

Afterwards, the teachers invite the whole class to freely speak, all questions no matter individual, group or remaining questions can be raised and the teachers give answer, the time is about 5 minutes. Finally, the teachers take several minutes to make 
simple conclusion to explain the questions omitted by the students, the questions need to be deepened and those need to be sublimated, and then finish the complete process.

\section{Effectiveness of the PAD Class model}

Although the PAD Class is easy to learn and use, it has achieved astonishingly good results. Since its first use in Spring 2014, it rapidly spreads to all provinces in China and even to Benin in Africa. In three years, it became popular countrywide and was widely applied in thousands of courses in hundreds of universities covering disciplines of social science, natural science, etc. It was also enlisted in teacher training programs of the Ministry of Education and Shanghai Board of Education, and it was appointed as a key subject in undergraduate teaching reform of Shanghai Municipality.

The PAD class was also fast introduced into basic education, producing many successful cases from grade 1 in elementary school to grade 12 in high school and highly approved by numerous teachers, and headmasters. With the PAD Class as subject, teachers have been granted more than 140 teaching reform projects and published 235 research papers.

Across the countries, the author organized more than 150 seminars promoting the PAD Class to tens of thousands of teachers. In Spring 2016, the author started to work with a publishing company to write a series of 17 manual books on the PAD class. The author wrote one book as an overall introduction of the paradigm including its theoretical background and its significance. Another 65 teachers from all over the country collaborated writing 16 books on how to use the PAD paradigm in different subjects courses, including 11 higher education subjects (psychology, biology, college English, arts, physical education, etc.) and 5 middle school subjects (Chinese, English, Math-Physics-Chemistry, Geography, etc.).

The fact that in such a short period of time, there can be so many successful cases 
of the PAD application in such a wide range of subject courses, the fact that such cases can be written up to give detailed instruction for other teachers to learn from, speak to its great duplicability, scalablity, and wide application.

There have been many rounds of teaching reforms in China in the past 20 years, both in K12 education and in higher education. But teachers and educators are generally not satisfied with the outcomes of such reforms. The extent to which they embrace the PAD Class and speed with which PAD spreads all over the country has no precedent in the history of education in China. This speaks to the quality of the PAD Class brings to the course of education as well as its relevance to the present day education reform.

\section{Innovation in the PAD Class}

A deep analysis shows that it involves theoretical innovation regarding the social relation between teacher and students. The lecturing paradigm over-emphasizes the authority of the teacher inhabiting the individuality and initiative of the students. The collaborative learning paradigm over-emphasizes the right of the students bringing chaos to learning. While one is too teacher-centered, the other is too student-centered, both are seriously flawed. If the power of control in the classroom all goes to the teacher, students are simply followers. If the power all goes to the students who are still growing, they do not have the full ability to exercise the power properly. The truth lies somewhere in the middle and the ideal solution is for the teacher and students to share the power.

Essentially, PAD Class reassigns the rights and responsibilities in teaching. It endows the deserved rights to the students, makes them undertake their responsibilities, represents the maximum respect to the students and brings democratic, dialogic, open and free atmosphere to the class, and therefore makes the class be more harmonious, comfort, full of fun and full of vitality. 
The PAD Class reshapes the power structure in the classroom, changing the social relation between the teacher and students forming a truly community of learning.

The second major innovation of the PAD paradigm is its decentralization of the so-called elite students and its respect of the so-called backward students. In the usual classroom, academic performance is considered the single most important criterion and all students are judged in reference with this one dimension. This will inevitably leads to a small number of "bright and excellent" students being praised and modeled after. In the PAD Class, performance is judged on a number of criteria including social skills like communication and collaboration, and more open-ended dimensions such as creative thinking, deemphasizing the importance of standard answers. This gives all students a room to show their advantages without necessarily having to compare themselves with the few "elite" students. As students are given sufficient time for independent study, females or minority students considered mistakenly as poor in some subject areas (e.g., STEM) can have more preparation time in advance and hence can perform better in the discussion than before, rising their self-esteem and learning motivation.

PAD Class has no special requirement on the basis, abilities and motivation of the students. Some teachers may think that PAD is not suitable due to the students have inferior basis, low abilities and insufficient study motivation. However, PAD is just needed to solve this problem since traditional teaching cannot achieve favorable effect on this kind of class. It is not to say that PAD is not utilized until the students have sound basis, high abilities and strong motivation. Rather, using PAD is to let the students regain the initiative of study, and then gain better basis and higher abilities and stronger motivation.

The key of success of PAD practice lies in more praise and encourage the backward students, do not criticize them and resolutely and bravely lower the requirements and the difficulty. The expectation and the requirements to the students 
shall be fair and reasonable. It shall implement "setting teaching by level of learning", determine the teaching content according to the students' practical level, not rigidly adhere to the textbooks or syllabus and abandon the teachers' self-centeredness, which is true respect to the students and the precondition to successful teaching.

There are also significant innovations in all major steps of the PAD procedure. For example, students' homework are no longer graded by correctness, the students are not allowed to ask questions until the end of group discussion. These features all represent major deviations from the classical teaching procedures and contribute to the effectiveness of the new paradigm.

\section{Summary}

To create a teaching paradigm that can preserve the advantages of the lecturing and collaborative learning paradigms and avoid their disadvantages, this is possibly the central challenge and most pressing issue to the current education system in the whole world. Changing from knowledge-based teaching to competency-based teaching, such a new paradigm will be oriented to the future education, in line with the transition from the industrial to the post-industrial society.

The PAD Class ensures that the students get adequate guidance. Different from traditional lecturing, the teacher should present the framework, the key principles and basic concepts, leaving space for the students to explore. After their independent study, students test, clarify and revise their individual learning outcomes with peers in the group discussion. With the emphasis on assimilation, the PAD Class integrates the lecturing paradigm and the discussion paradigm into a new one which has the pros of both but none of their cons.

Human civilization has entered a new era. PAD Class complies with humanity, releases people's potential, advocates personality, breeds creation so as to possibly bring a brand new education paradigm for the post industrialization era. 


\section{References}

[1] Michele, M., [Teaching at Stanford: an introductory handbook]. Denver, The center for teaching and learning, Stanford University, 29-32 (2007).

[2] Zhang, X. J., "The PAD Class, a new exploration in university classroom teaching reform," Fudan Education forum 12(5), 5-10 (2014).

[3] Crouch, C. H., and Mazur, E.,"Peer Instruction: Ten years of experience and results," American Journal of Physics 69(9), 970 (2001). 